\title{
INEQUALITIES INVOLVING CERTAIN FAMILIES OF INTEGRAL AND CONVOLUTION OPERATORS
}

\author{
Yong CHAN Kim AND H. M. SRIVASTAVA
}

\begin{abstract}
The main object of the present paper is to derive several strict inequalities associated with some families of integral and convolution operators which are defined for the class of normalized analytic functions in the open unit disk. A number of interesting consequences of these inequalities are also considered.
\end{abstract}

Mathematics subject classification (2000): 30C45, 26A33, 33B15.

Key words and phrases: Integral operators, convolution operators, analytic functions, Hadamard product or convolution, multiplier transformation, fractional integral, fractional derivative, Ruscheweyh derivative, Jack's lemma.

\section{REFERENCES}

[1] O. P. Ahuja AND H. Silverman, Function classes related to Ruscheweyh derivatives, J. Austral. Math. Soc. (Ser. A) 47 (1989), 438-444.

[2] M. K. Aouf, H. M. Hossen AND A. Y. Lashin, An application of certain integral operators, J. Math. Anal. Appl. 248 (2000), 475-481.

[3] T. M. FLETT, The dual of an inequality of Hardy and Littlewood and some related inequalities, J. Math. Anal. Appl. 38 (1972), 746-765.

[4] I. S. JACK, Functions starlike and convex of order $\alpha$, J. London Math. Soc. (Ser. 2) 3 (1971), 469-474.

[5] I. B. Jung, Y. C. Kim AND H. M. SRIVASTAVA, The Hardy space of analytic functions associated with certain one-parameter families of integral operators, J. Math. Anal. Appl. 176 (1993), 138-147.

[6] Y. C. Kim, K. S. LeE AND H. M. SRIVASTAVA, Some applications of fractional integral operators and Ruscheweyh derivatives, J. Math. Anal. Appl. 197 (1996), 505-517.

[7] Y. KomATU, On analytical prolongation of a family of operators, Mathematica (Cluj) 3255 (1990), $141-145$.

[8] S. S. Miller And P. T. Mocanu, Second order differential inequalities in the complex plane, J. Math. Anal. Appl. 65 (1978), 289-305.

[9] St. Ruscheweyh, New criteria for univalent functions, Proc. Amer. Math. Soc. 49 (1975), 109-115. 